Chapman University

Chapman University Digital Commons

Athletic Training Faculty Articles and Research

Athletic Training

$11-2016$

\title{
Creatine Kinase, Exertional Rhabdomyolysis, and Exercise-Associated Hyponatremia in Ultra- Endurance Athletes: A Critically Appraised Paper
}

Michelle A. Cleary

Chapman University, cleary@chapman.edu

Follow this and additional works at: http://digitalcommons.chapman.edu/athletic_training_articles Part of the Sports Sciences Commons

\section{Recommended Citation}

Cleary, M.A. (2016). Creatine kinase, exertional rhabdomyolysis, and exercise-associated hyponatremia in ultra-endurance athletes: A critically appraised paper. International Journal of Athletic Therapy and Training, 21(6), 13-15. doi: 10.1123/ijatt.2015-0071

This Article is brought to you for free and open access by the Athletic Training at Chapman University Digital Commons. It has been accepted for inclusion in Athletic Training Faculty Articles and Research by an authorized administrator of Chapman University Digital Commons. For more

information, please contact laughtin@chapman.edu. 


\section{Creatine Kinase, Exertional Rhabdomyolysis, and Exercise-Associated Hyponatremia in Ultra-Endurance Athletes: A Critically Appraised Paper}

\section{Comments}

This is a pre-copy-editing, author-produced PDF of an article accepted for publication in International Journal of Athletic Therapy and Training, volume 21, issue 6, in 2016 following peer review. The definitive publisherauthenticated version is available online at DOI: 10.1123/ijatt.2015-0071.

\section{Copyright}

Human Kinetics 
Running Head: Rhabdomyolysis in Ultra-Endurance Athletes

Creatine Kinase, Exertional Rhabdomyolysis, and Exercise-Associated Hyponatremia in Ultra-Endurance Athletes: A Critically Appraised Paper

Michelle Cleary, PhD, ATC

Chapman University

\author{
Direct Correspondence to: \\ Michelle A. Cleary PhD, ATC \\ Associate Dean of Graduate Programs \\ Crean College of Health and Behavioral Science \\ Chapman University \\ One University Drive \\ Orange, CA 92866 \\ Phone: 714-628-2797 \\ Email: cleary@chapman.edu \\ Submitted to: \\ International Journal of Athletic Therapy and Training \\ On:
}

September 1, 2015 
Running Head: Rhabdomyolysis in Ultra-Endurance Athletes

\section{BLIND TITLE PAGE}

Creatine Kinase, Exertional Rhabdomyolysis, and Exercise-Associated Hyponatremia in Ultra-Endurance Athletes: A Critically Appraised Paper 


\section{Creatine Kinase, Exertional Rhabdomyolysis, and Exercise-Associated Hyponatremia in Ultra-Endurance Athletes: A Critically Appraised Paper}

\section{Clinical Scenario}

Exercise-associated muscle damage results in elevated plasma creatine kinase (CK), often diagnosed as exertional rhabdomyolysis (ER) in runners. Likewise, exercise-associated hyponatremia $(E A H)$ is prevalent in ultra-endurance racers. A link has been proposed between $\mathrm{ER}$ and $\mathrm{EAH}$ in that the simultaneous presentation of EAH and ER creates a complicated and opposing treatment paradox regarding fluid resuscitation.

\section{Focused Clinical Question}

What is the relationship between EAH and ER in ultra-endurance athletes?

\section{Search Strategy}

- The database searched was Pub Med

- The following keywords were used: creatine kinase, athletes, muscle damage, exerciseinduced muscle damage and rhabdomyolysis

- The criteria for study selection were: human subjects, peer-reviewed, English language, published within last 2 years

- Critical appraisal was conducted according to the Oxford Center for Evidence-Based Medicine (OCEBM) and the Strengthening the Reporting of Observational Studies in Epidemiology (STROBE) statement.

\section{Study Selected}

- Chlibkova D, Knechtle B, Rosemann T, et al. Rhabdomyolysis and exercise-associated hyponatremia in ultra-bikers and ultra-runners. J Int Soc Sports Nutr. 2015;12:29.

DOI 10.1186/s12970-015-0091-x. Published online June 25, 2015.

\section{Evidence Quality Assessment}

This investigation utilized a multiple-group, non-randomized, cohort-control research design, or a Level $2 b$ according OCEBM. The STROBE statement was used to assess the quality of this study, which met 19/22 of the criteria.

Study Patients and Sampling. Subjects were 113 ultra-endurance athletes participating in a variety of ultra-events (ultra-mountain bikers: stage racers and 24-hr ultra-bikers; ultra-runners: 24-hr ultra- and 100-km ultra-runners). The study included 6 race finishers with rhabdomyolysis as diagnosed by blood CK levels $>10,000 \mathrm{U} / \mathrm{L}$ without the development of renal failure or necessity of medical treatment.

Control Group. The control group consisted of 100 normonatremic ultra-athletes who completed their respective event and provided a complete data set of blood and urine samples. Of the normonatremic finishers, 4 (4\%) ultra-runners (all men) developed ER.

Experimental Group. The researchers found 13 hyponatremic athletes diagnosed with postrace plasma $[\mathrm{Na}+]<135 \mathrm{mmol} / \mathrm{L}$ with $2(15.4 \%$, one man and one woman) who developed ER.

Outcome Measures. Athletes agreed to provide blood and urine measurements during registration the day before each race and upon completion of the race. Blood samples were analyzed for plasma $[\mathrm{Na}+],[\mathrm{K}+], \mathrm{CK}$, and urine creatinine; only $\mathrm{CK}$ and $[\mathrm{Na}+]$ are reported here. 


\section{Clinical Bottom Line(s)}

1. Of the ultra-endurance race finishers in this study $(n=113), 5.3 \%$ developed ER with CK $>10,000 \mathrm{U} / \mathrm{L}$ and $15.9 \%$ developed $\mathrm{ER} /$ myopathy (CK >2,000 U/L). Of the ultra-runners, $28.6 \%(6 / 21)$ developed ER and none of the ultra-mountain bikers. Hyponatremic ultraathletes developed ER more often than normonatremic ultra-athletes.

2. Due to the wide inter-individual ranges of $\mathrm{CK}$ and the excessively high $\mathrm{CK}$ in asymptomatic ultra-athletes, the value of CK as a prognostic or diagnostic tool is questionable.

3. In situations where the diagnosis of EAH is uncertain, treatment with fluid restriction is contraindicated in case of dehydration and ER which may lead to acute kidney injury.

\section{Implications for Practice, Education, and Future Research}

The overall incidence rate of ER was 5.3\% (6/113) in ultra-endurance race finishers and $28.6 \%$ $(6 / 21)$ of ultra-runners. Ultra-athletes who developed $\mathrm{ER}$ had an average post-race $\mathrm{CK}=$ $18,423.6 \pm 6,138.8 \mathrm{U} / \mathrm{L}$ (range=12,786.2-29,702.9 U/L). These ranges for post-race $\mathrm{CK}$ far exceed the 5-10 times upper limit of normal for CK for diagnosis of ER, indeed these athletes had 9,659.0 $\pm 8,793.3 \%(2,665.0 \pm 26,209.0 \%)$ increased CK from baseline. Further, the ultrarunners who did not present with ER also reported with exceedingly high CK, but were asymptomatic. The table below was calculated in aggregate from the data provided by the researchers and includes the plasma $[\mathrm{Na}+]$ and $\mathrm{CK}$ averages, ranges, and \% change from baseline for all ultra-race finishers. In the EAH and ER group, post-race CK increased $7,160.3 \pm 6,238.4 \%(2,749.0 \pm 11,571.5 \%)$ from pre-race while in the ER only group post-race CK increased $10,908.4 \pm 10,471 \%(2,665.0-26,209.0)$ from pre-race. In all the ultra-runners $(n=21)$ CK increased 3,365.8 $\pm 4,098.7 \%(990.7-5,782.1 \%)$ from pre-race while in all the mountain bikers $(n=82)$ CK increased $458.9 \pm 511.3 \%$ (308.1-590.9\%) from pre-race. The total finished ultra-marathons, total hours spent training weekly, and gender were related to post-race CK concentration $(P>0.05)$ in both groups.

Comments: The major strengths of this investigation were external validity or the generalizability of the sample of the large variety of ultra-endurance events and the number and quality of the variables assessed. Fortunately, none of the ultra-runners who developed ER required medical intervention. The major limitation of this investigation was the small sample size for the athletes who developed ER, as expected with the low incidence rate of this condition in well-trained athletes. Furthermore, the investigators did not confirm the presence of myoglobinuria, although this clinical indicator is less sensitive and not clinically useful. Finally, following the subjects for an additional $24-72 \mathrm{hr}$ would have likely demonstrated increased CK, a reliable clinical indicator of more severe rhabdomyolysis.

Appraised by:

Michelle A. Cleary PhD, ATC
Appraised on:

August 20, 2015 
Table. Post-race plasma sodium $[\mathrm{Na}+]$ and creatine kinase $(\mathrm{CK})$ in ultra-endurance athletes

\begin{tabular}{|c|c|c|c|c|c|c|c|}
\hline $\begin{array}{c}\text { Event } \\
\text { (gender) }\end{array}$ & & $\begin{array}{l}\text { Pre-Race [Na+] } \\
(\mathrm{mmol} / \mathrm{L})\end{array}$ & $\begin{array}{l}\text { Post-Race [Na+] } \\
\text { (mmol/L) }\end{array}$ & $\begin{array}{c}\text { \%change from } \\
\text { Pre-Race }\end{array}$ & $\begin{array}{l}\text { Pre-Race CK } \\
\text { (mmol/L) }\end{array}$ & $\begin{array}{c}\text { Post-Race CK } \\
(\mathrm{mmol} / \mathrm{L})\end{array}$ & $\begin{array}{c}\text { \%change from } \\
\text { Pre-Race }\end{array}$ \\
\hline \multirow{2}{*}{$\begin{array}{l}\text { Athletes* with } \\
\text { EAH } \\
\text { and ER } \\
(n=2, \text { all men) }\end{array}$} & $\mathrm{M} \pm \mathrm{SD}$ & $137.5 \pm 0.7$ & $133.5 \pm 0.7$ & $-2.9 \pm 0.0$ & $319.7 \pm 268.3$ & $14,842.9 \pm 466.7$ & $7,160.3 \pm 6,238.4$ \\
\hline & Range & $137.0-138.0$ & $133.0-134.0$ & -2.9 & $130.0-509.4$ & $14,512.9 \pm 15,172.9$ & $2,749.0 \pm 11,571.5$ \\
\hline \multirow{2}{*}{$\begin{array}{l}\text { Athletes }{ }^{*} \text { with } \\
\text { ER } \\
(\mathrm{n}=4,2 \text { men, } \\
2 \text { women) }\end{array}$} & $\mathrm{M} \pm \mathrm{SD}$ & $139.0 \pm 1.8$ & $138.0 \pm 2.4$ & $-0.7 \pm 3.0$ & $309.9 \pm 246.8$ & $20,213.9 \pm 7,065.0$ & $10,908.4 \pm 10,471.5$ \\
\hline & Range & $137.0-141.0$ & $135.0-141.0$ & -4.3 to 2.9 & $112.9-654.1$ & $12,786.2-29,702.9$ & 2,665.0-26,209.0 \\
\hline \multirow{2}{*}{$\begin{array}{l}\text { Ultra-Mountain } \\
\text { Bikers } \\
\text { ( } n=82,66 \text { men, } \\
16 \text { women) }\end{array}$} & $\mathrm{M} \pm \mathrm{SD}$ & $140.0 \pm 2.1$ & $138.1 \pm 2.3$ & $-1.3 \pm 1.9$ & $164.0 \pm 72.3$ & $828.2 \pm 657.8$ & $458.9 \pm 511.3$ \\
\hline & Range & $137.5-142.8$ & $136.6-140.0$ & -1.9 to -0.6 & $118.9-207.5$ & $418.1-1,316.3$ & $308.1-590.9$ \\
\hline \multirow{2}{*}{$\begin{array}{l}\text { Ultra-Runners } \\
\text { ( } \mathrm{n}=21,12 \text { men, } \\
9 \text { women) }\end{array}$} & $\mathrm{M} \pm \mathrm{SD}$ & $139.5 \pm 2.1$ & $137.7 \pm 2.5$ & $-0.6 \pm 2.2$ & $200.3 \pm 138.0$ & $5,156.8 \pm 6,079.2$ & $3,365.8 \pm 4,098.7$ \\
\hline & Range & $138.4-140.1$ & 136.0-139.1 & -1.7 to 1.3 & $99.0-251.1$ & 1,949.3-8,813.8 & $990.7-5,782.1$ \\
\hline
\end{tabular}
9 women)

Note. $\mathrm{EAH}=$ exercise-associated hyponatremia, ER= Exertional rhabdomyolysis

${ }^{*}$ All athletes who developed ER were ultra-runners 